\title{
PCR-RFLP Fails to Reveal Variability Within Schistosoma haematobium Detected in Loum (Cameroon) by Isoelectrofocusing Technique
}

\author{
Luogbou Nzu Deguy D'or ${ }^{1,2,3}$, Palmer Masumbe Netongo ${ }^{2,4,5}$, Nguemaïm Ngoufo Flore ${ }^{5}$, \\ Marc Kenmogne Kouam ${ }^{6}$, Louis-Albert Tchuem-Tchuente ${ }^{1}$, Wilfred Fon Mbacham ${ }^{2,4}$ \\ ${ }^{1}$ Centre for Schistosomiasis \& Parasitology, Yaounde, Cameroon \\ ${ }^{2}$ The Laboratory for Public Health Research Biotechnologies, University of Yaounde I, Yaounde, Cameroon \\ ${ }^{3}$ Department of Biochemistry, University of Bamenda, Bambili, Cameroon \\ ${ }^{4}$ Department of Biochemistry, University of Yaounde I, Yaounde, Cameroon \\ ${ }^{5}$ Department of Biomedical Science, University of Bamenda, Bambili, Cameroon \\ ${ }^{6}$ Department of Animal Sciences, Faculty of Agronomy and Agricultural Sciences, University of Dschang, Dschang, Cameroon
}

Email address:

luogbounzu@gmail.com (L. N. D. D’or)

\section{To cite this article:}

Luogbou Nzu Deguy D’or, Palmer Masumbe Netongo, Nguemaïm Ngoufo Flore, Marc Kenmogne Kouam, Louis-Albert Tchuem-Tchuente, Wilfred Fon Mbacham. PCR-RFLP Fails to Reveal Variability within Schistosoma haematobium Detected in Loum (Cameroon) by Isoelectrofocusing Technique. Biochemistry and Molecular Biology. Vol. 6, No. 3, 2021, pp. 35-39. doi: 10.11648/j.bmb.20210603.11

Received: June 4, 2021; Accepted: June 25, 2021; Published: July 9, 2021

\begin{abstract}
Schistosoma haematobium, which causes urinary schistosomiasis in humans is responsible for the largest number of infections in the word. Genetic variability among parasite populations is an important factor in their potential for producing harmful effects on the human populations they infect. In many areas, $S$. haematobium is sympatric with related schistosome parasites (most of other mammals) (i.e., S. bovis, S. mattheei, S. curassoni, S. intercalatum, S. guineensis and S. margrebowiei). PCR-RFLP analysis of ITS-2 rDNA loci is an usefull tools to detect hybrids amongs Schistosoma haematobium group. Many studies have been carry out in the town of Loum (Cameroon) in order to characterize Schistosoma haematobium species from this locality. However, no study based on PCR-RFLP analysis succeeds to detect any genetic variability as reported before using electrofocusing (IEF) technique. PCR-RFLP analysis realised on 10 isolates of Schistosoma haematobium from Loum reveals a DNA fragment of $501 \mathrm{bp}$ after amplification of ITS2 ribosomal gene. For all the samples, the enzymatic digestion of the mentioned DNA fragment gene with Taq I reveals two DNA bands of $158 \mathrm{bp}$ and $199 \mathrm{bp}$ which is characteristic of Schistosoma haematobium. In summary, molecular characterization of $S$. haematobium in Loum using PCR-RFLP approach reveals once more the absence of hybrids and no genetic variability. Further studies on a larger geographic scale involving many schools in Loum should be encouraged to screen more parasite isolates with different primers and molecular toolS. Information from such studies would provide better insight into the local lineages of $S$. haematobium. This knowledge might play a major role in establishing control strategies for urogenital schistosomiasis in Loum.
\end{abstract}

Keywords: Schistosoma haematobium, Genetic Variability, PCR-RFLP, Loum, Cameroon

\section{Introduction}

Schistosomiasis is a neglected tropical disease, caused by parasitic flatworms of the genus Schistosoma (subclass Digenea). Worldwide, approximately 779 million people are at risk of infection in endemic areas and more than 250 million people are estimated to be currently infected with
Schistosomiasis haematobium. [1]. More people are infected with $S$. haematobium than with all the other schistosome species combined. Of the 110 million cases of $S$. haematobium infection in sub-Saharan Africa, 70 million are associated with hematuria, 18 million with bladder wall pathology, and 10 million with hydronephrosis leading to severe kidney disease [2,3] and even bladder cancer [4]. 
Although morphologically S. haematobium is considered to be a uniform species, differences between parasite strains or populations have been observed in a number of biological characteristics such as infectivity [5], virulence [6], response to treatment [7] or fecundity [6]. The observed phenotypic variations have been attributed to genetic heterogeneity of the parasite [8].

The diversity of $S$. haematobium has been the subject of many molecular studies $[9,10]$ with one of the earlier study using enzyme analyses by isoelectric focusing in polyacrylamide gels [11] showing some variation and suggested mixing of parasite strains due to human population movementS. In Cameroon, many studies have been published on the strain of S. haematobium [12] which has replaced Schistosoma guineensis in the town of Loum through an exclusive competition [13] and introgressive hybridization [14]. Previous study indicates that $S$. haematobium found presently in Loum is a recombinant [12], more recently Luogbou and collaborators [15] used very few sample to indicate that there was no hybrid found in Loum. The current study aims to use more samples and investigate the presence of hybrids using PCR-RFLP approach.

\section{Materials and Methods}

\subsection{Ethical Considerations}

The study was approved by the National Ethics Committee of Cameroon (reference no. 072/CNE/DNM08) and was a public health intervention conducted by the Ministry of Health and the Ministry of Education. Stool and urine samples were collected from children in schools with the approval of the administrative authorities, school inspectors, directors and teachers. The objectives of the study were explained to the schoolchildren and to their parents or guardians from whom written informed consent was obtained. Children willing to participate were registered. Each child was assigned a unique identification number and results were entered in a database and kept confidential. All children who participated in the study were treated with PZQ at a dose of $40 \mathrm{mg} / \mathrm{kg}$. Other children were treated during the mass drug administration campaign implemented by the National Programme for the Control of Schistosomiasis and Intestinal Helminthiasis (NPCSIH).

\subsection{Study Area}

This study was conducted in LOUM Health District, Moungo Division, Littoral region of Cameroon), a semiurban setting situated at $70 \mathrm{Km}$ west of Douala the economic capital city of Cameroon (Figure 1). The coordinates of LOUM ranged from $180 \mathrm{~m}$ to $235 \mathrm{~m}$, latitude $4^{\circ} 43^{\prime} \mathrm{N}$ and longitude $9^{\circ} 43^{\prime} \mathrm{E}$. The city is surrounded by high mountains, hills and plateauS. It is crossed by the river Mbette which takes its source on Mount Koupé $(2070 \mathrm{~m})$ located to the north of the city. The soils are of volcanic origin and black texture over a large part of the communal territory. The climate is equatorial with a wet season of about 9 months
(March to November) and a short dry season (December to February). Precipitation is abundant (a mean of $2699 \mathrm{~mm}$ per year), while the mean monthly temperature fluctuates from $19^{\circ} \mathrm{C}$ to $25^{\circ} \mathrm{C}$. The soil type is very diverse but all from volcanic origin, that have developed to produce fertile soilS. There has been serious deforestation due to the activities of large plantations and small farmS. This is a farming area, with food crops and fruits farms adjacent to major industrial banana. This city is known as a high endemic zone for schistosomiasis and several authors have already taken urine or stool samples from schoolchildren in this city over the past forty years to study schistosome infections [16, 17]. According to Tchuem-Tchuenté et al. [16] the main sites of schistosomiasis transmission have been identified in areas adjacent to the Mbette river and its tributarieS.

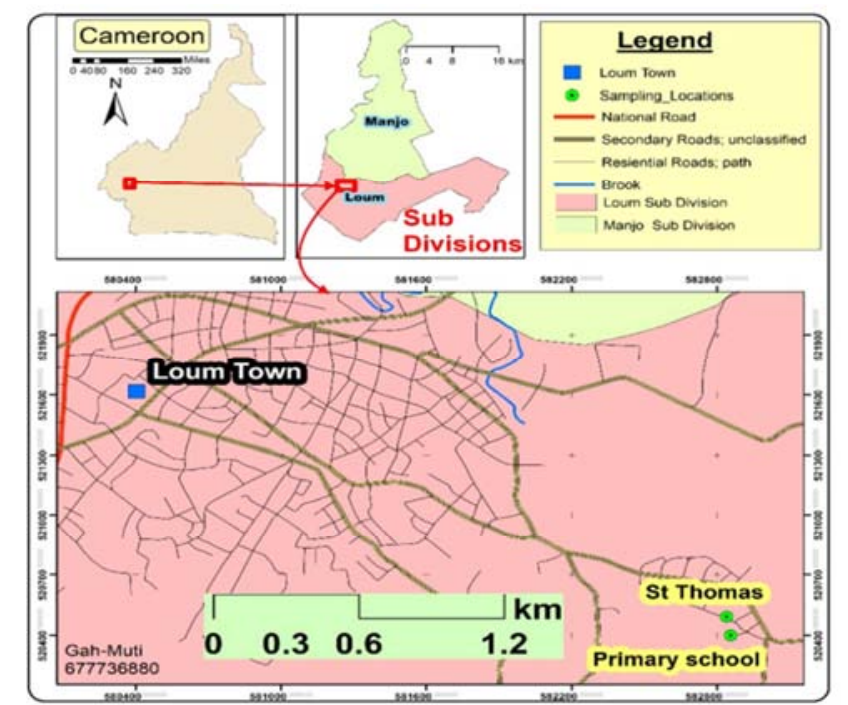

Figure 1. Map of LOUM showing the school where the samples analysed in this study were collected.

\subsection{Samples Collection}

\subsubsection{Collection of Adult Worms}

From 2008 to 2010, a cross-sectional survey was launched across the country to determine the prevalence of Schistosoma infection among school-aged children. Among the samples tested positive as described in Luogbou et al, [15], urine samples from 5 randomly selected infected children were chosen for further analysis in two schools: Primary School Bonkeng $(\mathrm{n}=3)$, and "St Thomas" Primary School $(n=2)$ (Table 1). Miracidia were hatched from eggs obtained from individual urine samples by sedimentation according to DBL (Danish Bilharziasis Laboratory) standard methods [18] and used to infect laboratory bred snails. Adult worms were obtained through the passage on mice in laboratory as described in Luogbou et al. [15]. For each sample, two adult worms male were analysed separately.

\subsubsection{DNA Extraction}

Genomic DNA extraction from all collected samples was performed as described by Luogbou and collaborators [15]. 
For each sample, one adult worm male was gently dried for 1 hour in a tank containing a desiccant. Next, $20 \mu \mathrm{l}$ of $250 \mathrm{mM}$ $\mathrm{NaOH}$ were added to each tube. After a 15 min incubation period at $25^{\circ} \mathrm{C}$, the tubes were heated at $99^{\circ} \mathrm{C}$ for $2 \mathrm{~min}$. Then, $10 \mu \mathrm{l}$ of $250 \mathrm{mM} \mathrm{HCl}, 5 \mu \mathrm{l}$ of Tris- $\mathrm{HCl}(500 \mathrm{mM})$ and $5 \mu \mathrm{l}$ of TritonX-100 (2\%) were added. A second heat shock at $99^{\circ} \mathrm{C}$ for 2 min was performed before products were stored at $-20^{\circ} \mathrm{C}$.

\subsubsection{DNA Amplification}

The ITS2 subunit (including most of the $5.8 \mathrm{~S}$ gene and 40 bases of the 5' of the $28 \mathrm{~S}$ gene) was amplified using two "universal primers" (Ransom Hill Bioscience Inc. Ramona, CA.) ITS-3 (5'-GCA TCG ATG AAG AACGCA GC-3') and ITS-4 (5'-TCC TCC GCT TAT TGA TAT GC$\left.3^{\prime}\right)$ [19]. PCR was undertaken in $25 \mu$ l volumes consisting of $250 \mu \mathrm{M}$ of each dNTP, $2.5 \mu \mathrm{L}$ of 10x PCR buffer 4 (New England Biolabs), $0.5 \mu \mathrm{M}$ of ITS-3 and $0.5 \mu \mathrm{M}$ of ITS-4 primers, $0.625 \mathrm{U}$ of Taq DNA polymerase (New England Biolabs), $18.25 \mu \mathrm{L}$ of $\mathrm{DdH}_{2} \mathrm{O}$ and $10 \mathrm{ng} / \mu \mathrm{l}$ of template DNA. Amplifications were done with the following cycling parameters: $94^{\circ} \mathrm{C}$ for $4 \mathrm{~min}, 30$ cycles of $94^{\circ} \mathrm{C}$ for $1 \mathrm{~min}, 50^{\circ} \mathrm{C}$ for $30 \mathrm{sec}, 72^{\circ} \mathrm{C}$ for $45 \mathrm{sec}$, and a final extension of $7 \mathrm{~min}$ at $72^{\circ} \mathrm{C}$ and then held at $4{ }^{\circ} \mathrm{C}$. One percent agarose gel electrophoresis with ethidium bromide staining was used to visualize and identify ITS-2-PCR productS.

\subsubsection{Restriction Fragment Length Polymorphism (RFLP) Analysis of the ITS-2 Regions}

The positive ITS-2 PCR products were digested with Taq 1 (New England Biolabs). Each RFLP reaction included $1 \mu \mathrm{L}$ of Taq1, $2 \mu \mathrm{L}$ of $10 \mathrm{x}$ Thermopol buffer, $0.2 \mu \mathrm{l}$ of BSA (10 $\mathrm{mg} / \mathrm{mL}$ ), $7 \mu \mathrm{L}$ of PCR product (approximately $300 \mathrm{ng} / \mu \mathrm{L}$ of DNA) and $9.8 \mu \mathrm{L}$ of $\mathrm{DdH}_{2} \mathrm{O}$, for a total volume of $20 \mu \mathrm{L}$ per reaction. The $T a q 1$ reactions were incubated at $65^{\circ} \mathrm{C}$ overnight [19]. The reactions were inactivated at $80^{\circ} \mathrm{C}$ for 20 min. $10 \mu \mathrm{L}$ of PCR-RFLP products were separated on $2 \%$ agarose gels, with molecular size markers of a 100-bp DNA Ladder (New England Biolabs). Fragments were sized by calculating their rate of flow in the gel and interpolation on the standard curve of rate of flow versus logarithm of molecular weight of the ladder.

\section{Results}

\section{PCR-RFLP analysis}

An ITS-2 DNA fragment of about $501 \mathrm{bp}$ was amplified from all the isolates of $S$. haematobium group and no difference in product size was observed as indicated in Figure 2.

The TaqI enzymatic digestion of the ITS-2 DNA fragment revealed only one profile as shown in Figure 3: Profile A (typical of $S$. haematobium) which constituted of 2 bands (158 bp and 199 bp (Table 1).

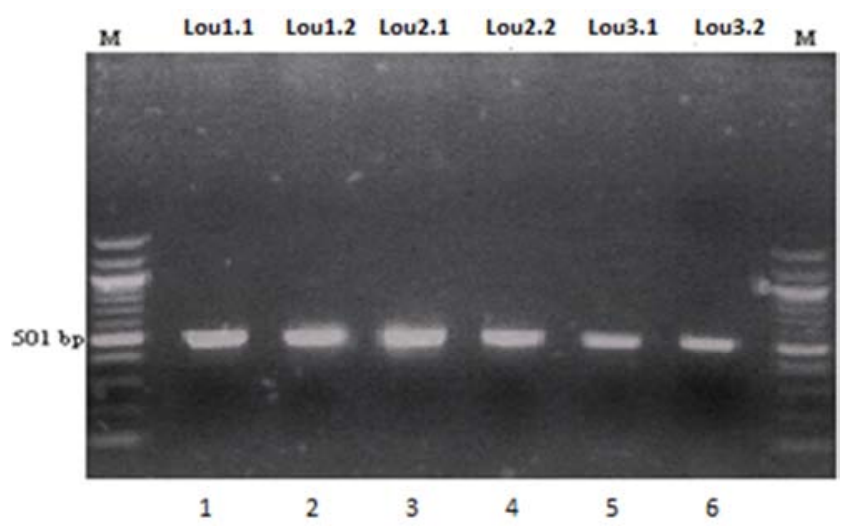

Figure 2. ITS2-PCR Profiles obtained from the samples analysed.

Legend: Gel electrophoresis of the amplified rDNA internal transcribed spacer (ITS-2) region of Schistosoma sp strains amplified by PCR. M $=100$ bp ladderS. Lou1.1, Lou1.2, Lou2.1, Lou2.2, Lou3.1 and Lou3.2 are all isolates from Primary School of Bonkeng in Loum. All samples from "St Thomas" Primary School gives the same results (not showing here).

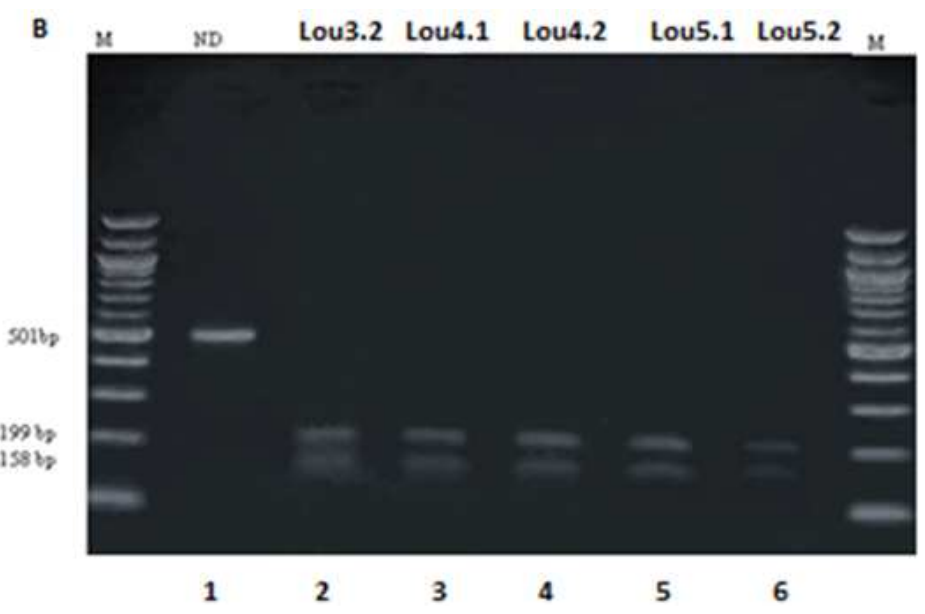

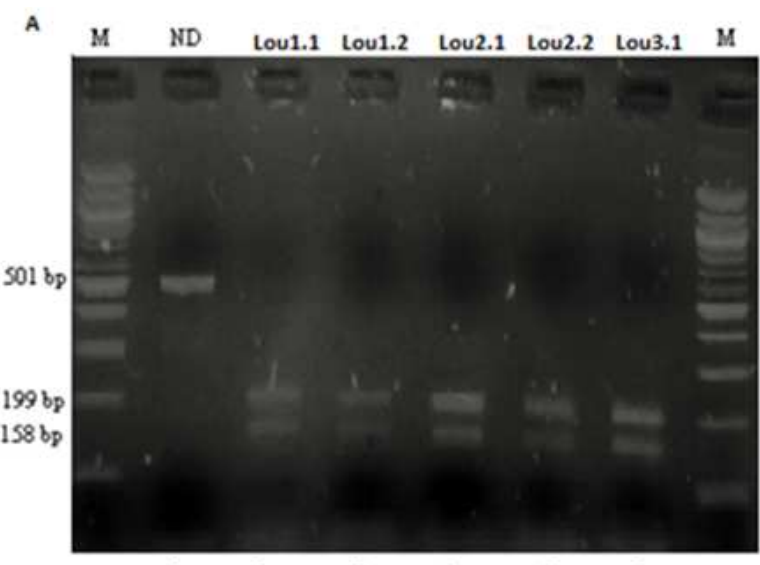

Figure 3. ITS-2 RFLP profile (A) obtained from the samples analysed.

Legend: Gel electrophoresis of the amplified rDNA internal transcribed spacer (ITS-2) region of Schistosoma sp strains digested with the TaqI. ND on lane A1 and B1 = Non digested, $\mathrm{M}=100$ bp ladderS. Lou1.1, Lou1.2, Lou2.1, Lou2.2, Lou3.1, Lou3.2 and Lou4.1, Lou4.2, Lou5.1, Lou5.2 are sets of isolates from Primary School of Bonkeng and "St Thomas" Primary School in Loum respectively. 
Table 1. DNA Bands size of ribosomal gene ITS2 after digestion using Taq I restriction enzyme.

\begin{tabular}{|c|c|c|c|c|c|c|}
\hline \multirow{2}{*}{ School } & \multirow{2}{*}{ Geographic Coordinnate } & \multirow{2}{*}{$\begin{array}{l}\text { Isolate } \\
\text { Code }\end{array}$} & \multicolumn{2}{|c|}{ Bands size after digestion with Taq I } & \multirow{2}{*}{ Ribotypes } & \multirow{2}{*}{ Classification } \\
\hline & & & 158 bp & 199 bp & & \\
\hline & & Lou1.1 & 1 & 1 & $\mathrm{~A}$ & S. haematobium \\
\hline & & Lou 1.2 & 1 & 1 & A & S. haematobium \\
\hline Primary School & Alt $242 \mathrm{~m}, \mathrm{~N} 04.70772^{\circ}$ & Lou2.1 & 1 & 1 & A & S. haematobium \\
\hline \multirow[t]{4}{*}{ Bonkeng } & $\mathrm{E} 009.74710^{\circ}$ & Lou2.2 & 1 & 1 & A & S. haematobium \\
\hline & & Lou3.1 & 1 & 1 & A & S. haematobium \\
\hline & & Lou3.2 & 1 & 1 & A & S. haematobium \\
\hline & & Lou4.1 & 1 & 1 & A & S. haematobium \\
\hline \multirow{3}{*}{$\begin{array}{l}\text { "St Thomas" Primary } \\
\text { School }\end{array}$} & Alt $232 \mathrm{~m}, \mathrm{~N} 04.70852^{\circ}$ & Lou 4.2 & 1 & 1 & A & S. haematobium \\
\hline & E009.74696 & Lou5.1 & 1 & 1 & A & S. haematobium \\
\hline & & Lou5.2 & 1 & 1 & $\mathrm{~A}$ & S. haematobium \\
\hline
\end{tabular}

$1=$ Presence of DNA Fragment.

\section{Discussion}

In this study, we used RFLP analysis of ITS-2 rDNA loci to identify adult schistosome worms isolated from Loum in Cameroon and to compare the results with previously obtained IEF (Isoelectrofocusing) results in the same locality. All the samples analysed indicate that only S. haematobiumis present in Loum with no hybrids found. This result agrees with a previous study [15] that reported the absence of schistosoma hybrid in Loum using the same RFLP approach. However, this study shows contradicting results with our previous study that showed genetic variability of $S$. haematobium using IEF. A total of 10 adult worms from 5 samples were analysed in this study compaired to the most recent study [15] where only 2 samples were analysed indicating that the size of the sample is not the justification.

Unlike our findings, other studies based on G6PD pattern showed in Loum, the genetic variability of $S$. haematobium [20] and the presence of S. haematobium $-S$. guineensis hybrids [21].

Our result is not also in line with the study of Webster and collaborators [12] which demonstrates the presence of pure $S$. haematobium and the recombinant in Loum using a singlestrand conformation polymorphism (SSCP) approach for investigating genetic interactions of Schistosoma haematobium and Schistosoma guineensiS. The absence of genetic variability in this study may be due to the limitation of PCR-RFLP approach which is not the suitable technique for intraspecifique variation.

Our study, in spite of its limitations, expresses the need to assess the genetic variability of schistosoma population. In fact, the level of genetic variability is a significant measure for assessing the effects of selective pressure generated by drug therapy control measureS. Hence, high genetic variability may provide a sizable genetic basis for selection to increase the rate of development of praziquantel resistance [22].

\section{Conclusion}

In summary, our study on molecular characterization of $S$. haematobium in Loum using PCR-RFLP approach reveals that they were neitheir hybrids nor genetic variability. Further studies on a larger geographic scale involving many schools from study area are necessary in order to isolate and screen more parasite using different primers and molecular toolS. Results from such studies might provide better insight into the local lineages of $S$. haematobium and might play a major role in establishing control strategies for urogenital schistosomiasis in Loum.

\section{Competing Interests}

The authors declare that they have no competing interestS.

\section{Author Contributions}

LND and PMN conceived the study. LND and PMN wrote the first draft of the manuscript. LND and PMN performed the molecular analyseS. LND, PMN and NNF revised the manuscript. All authors read and approved the final manuscript prior to submission.

\section{Acknowledgements}

The authors acknowledge the support from the European Union for the CONTRAST project FP6 STREP no. 032203. The funders had no role in study design, data collection and analysis, decision to publish, or preparation of the manuscript.

\section{References}

[1] Molyneux DH, Savioli L, Engels D. (2017). Neglected tropical diseases: progress towards addressing the chronic pandemic. Lancet. 389 (10066): 3 12-325. doi: 10.1016/S0140-6736(16)30171-4.

[2] King CH, Dickman K, Tisch DJ (2005). Reassessment of the cost of chronic helmintic infection: A meta-analysis of disability-related outcomes in endemic schistosomiasiS. Lancet 365: 1561-1569.

[3] Van der Werf M J, Bosompem KM, de Vlas SJ (2003) Schistosomiasis control in Ghana: Case management and means for diagnosis and treatment within the health system. Trans R Soc Trop Med Hyg 97: 146-152. 
[4] Lucio Lara S. , Julio Santos, Maria joao G., Carina Bernardo, Carlos Lopes, Gabriel Rinaldi, Paul J. Brindley and José M. Correia da Costa (2021). Urogenital schistosomiasis-History, pathogenesis, and bladder cancer. Journal of Clinical Medecine, 10 (2): 205 Doi: 10.3390/Jcm10020205.

[5] Sire C, Durand P, Pointier J. P, Theron A, (1999). Genet-ic diversity and recruitment pattern of Schistosoma mansoni in a Biomphalaria glabrata snail popula-tion: a field study using randomly-amplified poly-morphic DNA markerS. Journal of Parasitology, 85: 436-441.

[6] Mohammed A. Afifi, Asif A. Jiman-Fatani, Nabeel H. AlHussainy, Mohammed W. Al-Rabia, Anas A. Bogari (2016). Genetic diversity among natural populations of Schistosoma haematobium might contribute to inconsistent virulence and diverse clinical outcomeS. Journal of Microscopy and Ultrastructure, 4: 222-227.

[7] Gryseels B, Polman K, Clerinx J, Kestens L. (2006). Human schistosomiasiS. Lancet, 368: 1106-1118.

[8] Curtis J, Sorensen R E, Kristen P L, Minchella D J, (2001). Microsatellites loci in human blood fluke Schistosoma mansoni and their utility for other Schistosome specieS. Molecular Ecology, 1: 143-145.

[9] Webster BL, Diaw OT, Seye MM, Webster JP, Rollinson D. (2013) Introgressive Hybridization of Schistosoma haematobium Group Species in Senegal: Species Barrier Break Down between Ruminant and Human SchistosomeS. $\begin{array}{lllll}\text { NeglTrop Dis, } 7 \text { (4): } & \text { e2110. doi: }\end{array}$ 10.1371/journal.pntd.0002110.

[10] Tom Pennance, Fiona Allan, Aidan Emery, Muriel Rabone, Jo Cable, Amadou Djirmay Garba, Amina Amadou Hamidou4, Joanne P. Webster, David Rollinson and Bonnie L. Webster (2020). Interactions between Schistosoma haematobium group species and their Bulinus spp. intermediate hosts along the Niger River Valley. Parasites Vectors, 13: 268 https://doi.org/10.1186/s13071-020-04136-9

[11] Wright C A and Ross G C (1983). Enzymes in Schistosoma haematobium. Bull WHO 61: 307-316.

[12] Webster BL, Tchuem Tchuenté LA, Southgate VR.(2006) A single-strand conformation polymorphism (SSCP) approach for investigating genetic interactions of Schistosoma haematobium and Schistosoma guineensis in Loum, Cameroon. Parasitology research, DOI 10.1007/s00436-0060310-0.

[13] Tchuem Tchuenté LA, Morand S, Imbert-Establet D, Delay B, Jourdane J. (1996) Competitive exclusion in human schistosomes: the puzzling restricted distribution of Schistosoma intercalatum. Parasitology, 113: 129-136.
[14] Tchuem Tchuenté L A, Southgate V R, Njiokou F, Njiné T, Kouemeni L E, Jourdane J, (1997). The evolution of schistosomiasis at Loum, Cameroon: replacement of Schistosoma intercalatum by $S$. haematobium through introgressive hybridisation. Transactions of the Royal Society of Tropical Med-icine and Hygiene, 91: 664-665.

[15] Luogbou Nzu D D, Netongo Masumbe Palmer, Bayemi Pougue Henri, Mbacham Fon Wilfred and Tchuem Tchuente Louis-Albert (2015). Detection of hybrid Schistosoma haematobium group species in Cameroon by PCR-RFLP of the second internal transcribed spacer (ITS-2). Word journal of pharmaceutical Research 4 (6): 1961-1980.

[16] Tchuem Tchuenté LA, Behnke JM, Gilbert FS, Southgate VR, Vercruysse J. (2003). Polyparasitism with Schistosoma haematobium and soil-transmitted helminth infections among school children in Loum, Cameroon Trop Med Int Health. 8 (11): $975-86$.

[17] Southgate Vaughan R, Van Wijk Henry B, Wright Carol A. (1976). Schistosomiasis at Loum, Cameroun: Schistosoma haematobium, S. intercalatum and their natural hybrid Z Parasitenkd. Apr 30; 49 (2): 145-59.

[18] Christensen NØ, Gøtsche G, Frandsen F (1984). Parasitological Techniques for Use in Routine Laboratory Maintenance of Schistosomes and for Use in Studies on the Epidemiology of Human and Bovine SchistosomiasiS., Danish Bilharziasis Laboratory, Charlottenlund, WHO Collaborating Centre for Applied Malacology and Schistosomiasis Control. 1984; 2-10.

[19] Barber E, Mkoji GM, Loker ES (2000). PCR-RFLP analysis of the ITS 2 region to identify Schistosoma haematobium and S. bovis from Kenya. Am J Trop Med Hyg, 62 (4): 434-440.

[20] Luogbou Nzu D. D., Netongo Palmer M., Mbacham Wilfred F. and Tchuem Tchuente Louis-Albert (2013). Preliminary studies on the variability of Schistosoma haematobium Glucose-6-Phosphate Dehydrogenase by Isoelectric Focusing. Cameroon Journal of Biological and Biochemical Sciences, 21 (1): 21-26.

[21] Webster B. L., Southgate V. R., Tchuem Tchuenté L. A. (2003). Isoenzyme analysis of Schistosoma haematobium, $S$. intercalatum and their hybrids and occurrences of natural hybridisation in Cameroon. Journal of Helminthology, 77: 269-274.

[22] Gower CM, Gouvras AN, Lamberton PH, et al (2013). Population genetic structure of Schistosoma mansoni and Schistosoma haematobium from across six sub-Saharan African countries: implications for epidemiology, evolution and control. Acta Trop. 128 (2): 261-274. doi: 10.1016/j.actatropica.2012.09.014. 